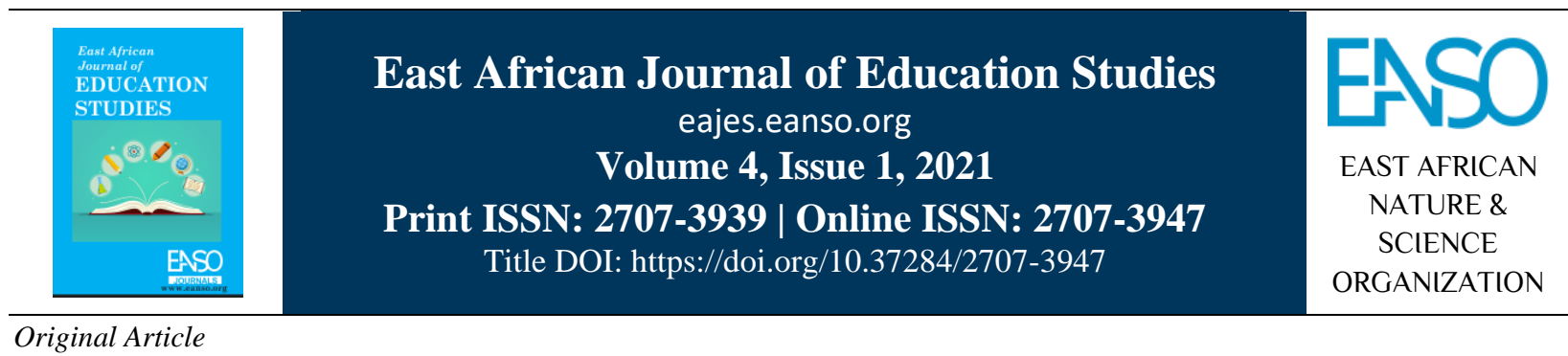

\title{
The Challenges and Benefits of Discussion Method of Teaching History Lesson at Teachers' Training Colleges: Injibara College of Teachers Education in Focus.
}

\author{
Wondim Tiruneh Zeleke \\ ${ }^{1}$ Injibara College of Teachers' Education, Injibara, Ethiopia. \\ *Author for Correspondence Email: wondimzeleke@ gmail.com.
}

Article DOI: https://doi.org/10.37284/eajes.4.1.506

Date Published: ABSTRACT

14 December 2021 The study was conducted based on primary and secondary sources of data. To achieve the objectives of the study, I used qualitative research methods.

Keywords: The techniques employed in the study were Semi-structured Interviews, Observations, Focus Group Discussions, and Document Analysis. The Challenges, researcher has also consulted written materials such as books, articles, Benefits, reports, research papers, and related researches in order to fill historical gaps.

Methods of Teaching, Group Discussion, The findings indicated that although many instructors and students have Critical thinking. positive attitudes towards the benefits of learning history through the discussion method, there are some teachers and students interested in teaching and learning through the lecture method.

\section{APA CITATION}

Zeleke, W. T. (2021). The Challenges and Benefits of Discussion Method of Teaching History Lesson at Teachers' Training Colleges: Injibara College of Teachers Education in Focus. East African Journal of Education Studies, 4(1), 98-106. https://doi.org/10.37284/eajes.4.1.506.

\section{CHICAGO CITATION}

Zeleke, Wondim Tiruneh. 2021. "The Challenges and Benefits of Discussion Method of Teaching History Lesson at Teachers' Training Colleges: Injibara College of Teachers Education in Focus”. East African Journal of Education Studies 4 (1), 98 -106. https://doi.org/10.37284/eajes.4.1.506.

\section{HARVARD CITATION}

Zeleke, W. T. (2021) "The Challenges and Benefits of Discussion Method of Teaching History Lesson at Teachers' Training Colleges: Injibara College of Teachers Education in Focus", East African Journal of Education Studies, 4(1), pp. 98-106. doi: 10.37284/eajes.4.1.506.

\section{IEEE CITATION}

W. T. Zeleke, "The Challenges and Benefits of Discussion Method of Teaching History Lesson at Teachers' Training Colleges: Injibara College of Teachers Education in Focus”, EAJES, vol. 4, no. 1, pp. 98-106, Dec. 2021.

98 This work is licensed under a Creative Commons Attribution 4.0 International License. 


\section{MLA CITATION}

Zeleke, Wondim Tiruneh. "The Challenges and Benefits of Discussion Method of Teaching History Lesson at Teachers' Training Colleges: Injibara College of Teachers Education in Focus". East African Journal of Education Studies, Vol. 4, no. 1, Dec. 2021, pp. 98-106, doi:10.37284/eajes.4.1. 506.

\section{INTRODUCTION}

Teaching methods as Khalid Abdulbaki1 sighted in Burden (2010) are approaches to teaching and learning in which concepts, patterns, and abstractions are taught in the context of strategies that emphasise concept learning, inquiry learning, and problem-solving learning (Khalid, 2018, p. 118). The teaching method comprises the principles and methods used for instruction to be implemented by instructors to achieve the desired learning by learners. These strategies are determined partly by the subject matter to be taught and partly by the nature of the learner. For a particular instructional method to be appropriate and efficient, it has to be in relation to the characteristic of the learner and the type of learning it is supposed to bring about as well as how learners learn (Amina, 2017, p. 4). In the discussion method, the instructor leads or guides the learners in expressing their opinions and ideas with a view to identifying and solving problems collectively (Amina, 2017, p. 4).

Discussion methods of teaching could be one of the available teaching methods carried out by university lecturers (Khalid, 2018, p. 119) to promote learning. However, the dynamics of the discussion technique may not be realised by most of the lecturers at the universities. Research on the efficiency of group discussion methods has shown that team learning and student-led discussions produce favourable student performance outcomes and foster greater participation, self-confidence, and leadership ability (Khalid, 2018, p. 119). Teachers thought of discussion as recitation, a teacher-directed conversation, an open-ended conversation, a series of challenging questions, a guided transfer of knowledge, and practice at verbal interaction. Classroom discussion serves several educational purposes because it is a unique form of classroom talk and a very special group dynamic, and then discussion requires students and teacher to talk back-and-forth at a high cognitive and affective level, both with one another and the subject matter being discussed (Bruce, 1997, p. 3-4).
The discussion teaching method is a design that provides an opportunity for discussion between teacher and students and students to students. It is a strategy that centres on shared conversations, discussions, and the exchange of ideas in class. It gives an opportunity for all to sit and listen, as well as talk and thinks, thus emphasising the process of "coming to know" as valuable as "knowing the right answer" (Sadker, 1991).

In other words, students in a discussion class are not passive listeners, neither is the teacher a sole performer. Students are allowed to develop critical thinking abilities, learn to evaluate ideas, concepts and principles, procedures, and even programmers and policies based on clearly set criteria (Sadker, 1991).

Most of the trainees who attend History classes at Injibara College of Teachers Education fail to express historical terms independently, especially in spoken and written activities. Plenteous reasons can be mentioned behind the issues in such a case that; problems related with their background knowledge which may be less in understanding contextually, problems related with school environment where they came across, problems related with poor curriculum design, problems related with poor methodology, the insufficient material provision that appealed to retard the communicative aspect of teaching history, the existing incompetent and less motivated teachers, lack of interest and poor background of the trainees, social and economic predicaments of the trainees and other related factors (Interview with students).

\section{NEW EDUCATIONAL TRAINING POLICY AND ITS APPROACH}

As indicated in Birhanu (2019, p. 3), the New Educational Training Policy was designed in Ethiopia in 1994 and introduced a lot of changes in the implementation of educational activities. Then, by realising the importance of an effective teachinglearning approach in empowering the quality of Ethiopian human learning, the government of Ethiopia has decided on an active learning approach 
where cooperative learning to be one of the compulsory strategies for educational levels. To enable students to improve their learning ability, it is necessary to implement the Collaborative method of teaching to encourage students to communicate as effectively as possible (Birhanu, 2019, p. 3).

The majority of studies indicated that positive results in relation to achievement when using cooperative learning in comparison with traditional methods, still argue that there is a need for further research on the practice and challenges of cooperative learning approach in different stages and curriculum. Some of the challenges are connected with the potential difficulty in carrying out Cooperative Learning in large class sizes, improper classroom organisation, problems related to background knowledge, lack of necessary teaching materials, well-trained instructors, etc. (Najmonnisa, 2013).

I agreed with the ideas described by Aschalew due to the fact that the study has been chosen for a number of reasons. In the first place, there are educational aspects since it could be helpful to know whether active teaching-learning methods can have an impact on what instructors who are familiar with traditional teaching methods plan and do in their history lessons when attempting to use them. Secondly, in academic terms, studies on the use of active learning, for instance, group discussion, in Ethiopian higher education are considered to be still in their infancy (Aschalew, 2013, p. 370-390).

\section{THEORETICAL FRAMEWORKS}

Many researchers believe that learning through discussion method have been focused on determining the effects where these methodological strategies have in specific areas of the curriculum. Thus, they have been developed and applied in different subjects, such as Social and Natural Sciences. However, it is in the field of history where collaborative learning has been used more, perhaps due to the high level of failure that this subject involves in almost all the countries in the world (Santiago, 2003, p. 95).

The discussion method is an interactive learning process that encourages learners to think critically and creatively at higher cognitive levels. The use of this method according to Amina (2017, p. 12), is consensus learning and encourages participatory learning where participants put their ideas together and contribute meaningful ideas that can help to conclude on a topic. Both the instructor and the learners discuss the pros and cons of the problem and then arrive at some tangible conclusion. Thus, "discussion is a thoughtful consideration of relationship involved in the topic or the problem under study. These relations are to be analysed, compared, evaluated and conclusions are drawn. The discussion requires a statement or enumeration of the facts to be analysed. In discussion, mere allegations unsupported by evidence are of little value.

Amina (2017) revealed that most studies have shown that the discussion method is very important in social studies teaching and learning because of its nature of education. Naturally, social studies provide the ground for group discussion. The majority of the issues discussed consist of social issues and day-to-day happenings that affect both instructors and learners alike. Bello (1981) described the discussion method of instruction as the verbal exchange of views, opinions, or ideas between two or more people. This activity that the instructor gives the learners a topic to discuss in the class is what takes place in the discussion method.

A lecturer who is a good discussion leader could be equipped with some kind of general plan. As a result of the comments or questions the students may raise in class, experienced lecturers may find it appropriate to modify or change their aims during a discussion (Khalid et al., 2018, p. 120). Without a general plan at the start of a class, it may be difficult to make such prompt decisions. In order to start a constructive class discussion, a lecturer could spend more time and effort to prepare thoroughly for a discussion than for a lecture. Although the students present the ideas, lecturers may have sufficient knowledge of the subject matter to be able to absorb the flow of ideas. They must be aware of ideas that may lead the lecturers off on a tangent and direct the discussion away from these ideas. The lecturer may also guide the students away from irrelevant ideas and toward the desired aims without dominating the whole discussion (Khalid et al., 2018, p. 120). 
Classroom discussion serves several educational purposes because it is a unique form of classroom talk and a very special group dynamic. Discussion requires students and teachers to talk back-and-forth at a high cognitive and affective level, both with one another and the subject matter being discussed. Dillon explains this by stating, "What they talk about is an issue, some topic that is in question for them. "Their talk consists of advancing and examining different proposals over the issue" (Bruce, 1997, p. 3).

When considering discussion as a curriculum outcome, students' participation in the actual discussion becomes an end in itself. By teaching students how to discuss, the benefits of using discussion in the classroom can be extended to all areas of students' lives. The research on how teachers "teach discussion" is limited. Most that are available is related to citizenship education because discussion provides one way for citizens to interact (Barber, 1989, p. 355-356). If students or citizens are to engage in discussions that allow for the development of opinions and positions on issues common to a group, then competence in the skills of discussion is required. The very act of discussing requires participants to interact in a particular and structured manner. These structured interactions will likely be different from interactions during debates or arguments (Bruce., 1997, p. 6). The beneficial effects of learning through group discussion are not limited to academic gains. Small groups allow students to interact with their peers and consequently enhance social skills. The structured processes involved in cooperative learning promote pro-social skill development and have been linked to gains in student self-esteem (William, 2012, p. 241).

\section{METHODOLOGY}

This research was conducted based on the qualitative approach. Because the qualitative approach was considered more relevant to undertake this research as it allowed greater capacity to gain more depth and meaningful evidence from the informants as regards the low participation of Students through the discussion method of teaching history lessons. Both primary and secondary data sources are utilised. The techniques employed in the study were Semi- structured Interviews, Observations, Focus Group Discussions, and Document Analysis. The study examined Room 17- first-year regular history department students' conceptions of classroom discussion and their purposes for using classroom discussion. The participants were selected through the purposive sampling method, as purposive sampling is an appropriate sampling technique to choose participants for qualitative case study design because it will point out participants who can discover, understand and gain deep insights about the issue under study. Here, in qualitative research, sites and participants that are believed to give the investigator the best opportunity to understand the problem and the research question are purposefully picked.

\section{FINDINGS AND DISCUSSION}

\section{Designed Strategies before and during Discussion}

Before conducting the research, the researcher evaluated the participation of students while the teaching-learning process has been undergoing in the linear history classroom. Accordingly, the researcher found the classroom environment which was calm. During the interaction, some of the students were jotting the main points from the blackboard, while some others were talking with the nearby seats without considering the classroom teacher as their teacher. Some others were captured while doing the home works for other subjects. During the evaluation, many of the classroom students' responses seemed out of mind is out of sight. Therefore, depending on their classroom participation and test scores, I compared the class with other related sections, and then the history test score registered by the class (Room-17 first-year regular history class) is relatively lower than other sections of the same grade. This and other related factors initiated me to conduct research in the class where the classroom participation and the test result are low.

Generally, to encounter the problems related to the participation of the trainees in history class and promote active learning in the College environment, the teacher-educator has re-arranged the classroom students into 'Six' separate groups, each group having 'Five' members. Therefore, to achieve the 
afro- mentioned goals, the active participation of students should be taken into consideration. That is why; I concentrated my attention on improving the participation of students through discussion method of teaching history; to bring meaningful teachinglearning process, to make the students familiar with the subject matter, to improve their face-to-face communication or intrapersonal skills, to create participatory, conductive and communicative learning place, and to discover (innovate) new knowledge and skills to their practical environment.

\section{Results of Students' Interview and Observations}

The capacity to elicit more information from the participants, Semi-structured interview permits scope for the informants to answer questions more on their terms than the standardised interview permits, yet still provides a good structure for comparability over that of the focused interview.

Most of the students stated that learning and teaching history lessons by using discussion methods could give them confidence in enhancing their cognitive aspects and freedom for free communication inside and outside the classroom. They agree in regard to their ability to identify ideas during the discussion and broaden their general knowledge, yet some are less assured whether they are able to analyse information, extract detailed opinions or compare their ideas with the others. Students affirmed that they develop self-confidence during the discussion, state opinions without hesitation, and are motivated to participate in future discussions. Yet, some students were less confident in presenting their opinions as they preferred to wait for the lecturer to encourage them to do so or other students to carry out the task.

Many students admired the effect of the group discussion method of teaching and learning history lessons for the fact that the new classroom atmosphere encouraged them to learn. For instance: a Positive overview of the group work leads them to fruitful learning, doing topic-related activities and exercises makes them more participants and investigatory, doing mistakes for them during the discussion is not a loss of face rather opportunities for good learning.

Students believe that classroom discussions will help them better understand about the subject matter more clearly because the process of talking clarifies their thinking. Many teachers facilitate discussions in an attempt to expose their students to multiple perspectives on a topic and to determine how well students understand perspectives other than their own. The majority of the students are not interested in participating in group work. From this point of view, the researcher generalises that the traditional style of students' learning and their lack of interest are major problems facing the classroom instructor while he/she was implementing group discussions during an interaction. However, the results of students' interviews and observations were vital indicators of the effect of group discussion in the classroom. Most participants responded that they like doing tasks cooperatively with their classmates than doing individually. Teachers believe that the process of discussing develops students' thinking skills and increases student motivation to make connections between what they talk about in school and what is happening in the world around them. The result is more in-depth learning about a topic, which helps students recognise connections between topics and concepts rather than merely comparing facts.

\section{Results of Interview with Instructors}

The interviews with instructors indicate that group composition may be a key factor behind students' academic performance. Many teacher informants described that many students preferred group-based teaching and learning of history for developing students' interpersonal skills. However, when some group members did not participate and provide help to others or when all group members were weak students and they could not complete the group's task, a small number of students preferred the lecturing method of learning and individual works done.

Teachers' conceptions of discussion are based in part on what they hope to accomplish during a lesson. Each conception of discussion becomes more or less viable as a method of instruction in relation to teachers' purpose.

Teacher educators and Academic administration should consider teaching the discussion method because of its potential to enhance student learning and democratic citizenship. Through classroom discussions, students might develop abilities to 
interact with others about issues of common interest.

Students, thought of as citizens-in-process, might learn how to engage in discussions with classmates of different races, genders, social statuses, and abilities and allow equal participation by every student.

Additionally, teacher informants suggest that students learn subject matter better when they are required to organise it themselves and develop an individualised understanding of the concepts being taught. As one teacher said, "students have to have knowledge of a topic before they can talk about it. Moreover, teacher informants report that they use discussion as a method of instruction: encouraging students to build their knowledge of the subject matter and exposing students to multiple perspectives.

Discussion is a valuable tool for teachers to have in their collection of instructional methods, especially in light of long-standing calls for educators to teach problem-solving skills and to promote conceptual understanding of the material.

Using classroom discussion as either a method or as an outcome is a difficult task for teachers. Teachers' roles during the discussion are critical to the purpose of the discussion, even when the discussion appears to be student-driven (e.g., when it encourages student-to-student interactions).

Before the discussion begins, teachers should determine the purpose of the discussion, their role during the discussion, and how to facilitate the types of interactions they want to have. When the discussion is used as a method, teachers will be focused on the content and comments of the students.

When the discussion becomes an outcome, teachers turn their attention more to the interactions of the students and less to the content of the discussion. Instructing pre-service and in-service teachers explicitly about discussion and the purposes served by using and teaching discussion could encourage its effective use in the classroom. Teachers reported that discussions build knowledge if they intellectually engage students. In other words, the topic of the talk had to be of interest to the students.
It is the engagement that teachers believe encourages students to develop deeper understandings of the subject matter. Additionally, engaging discussions increase student motivation to make connections between what they talk about in school and what is happening in the world around them. While the discussion is used to clarify the subject matter for students, teachers also use classroom discussion to present subject matter to students who are not well prepared for the class. Five informant teachers stated their frustration that students often come to class without having completed their home take reading assignments as a given historical topic is concerned. These teachers admitted to a form of defensive teaching where they lowered their expectations for student preparation and spent time during class discussions to explore the subject matter. Group efforts require students to interact on an interpersonal level.

In many cases, students must be taught skills such as how to lead, resolve conflict, build trust, and effective decision making. Although logic would suggest that effective social skills would be present during successful group learning, identifying and quantifying these skills proved to be elusive in the research utilised in this review. Therefore, for improving their group and individual participation in history class, the teacher informants have stated to apply the following methods: applying different teaching techniques depending on the class situation, making them reflect on independent and group related tasks in the classroom turn by turn, rearranging many tutorial classes and encouraging them to attend the class regularly, giving different reading assignments and text book-related activities during and after the class, allowing them to sit based on the mixed ability grouping in each and every history classes, giving advice that can initiate them to become competent for their future vision, etc.

\section{Results of Focus Group Discussions (FGD)}

Results of the focus group discussion indicate that active learning in the form of group discussion before, during, and after the classroom is the most instrumental for developing not only the skills but also social understandings within a given community. Additionally, group processing occurs when students are able to self-evaluate the structure, workings, and accomplishments of the group. 
During group processing, students can identify the strengths and weaknesses of the group in terms of collaboration, defining the problem, and overall achievement. Group processing is viewed as an essential part of the cooperative learning experience. Moreover, throughout my experience, I had observed many history teachers from high school when they were ordering the students to jot down necessary information/main points/ from history textbooks by themselves individually unless they may get the least marks from their exercise book at the end of the semester. Therefore, the classroom students must jot down necessary information from the textbooks what they were being told to do so without understanding. Then, when teachers teach history in this way, it creates not only boring but also confusion about what they are doing.

But instead of doing arbitrarily, the roles of history teachers should be: Assisting the classroom students in solving the problems and facilitating the historical investigation of students in history class, encouraging students to observe the relationships in different historical situations, similarities, and differences, causes and effects, encouraging the students to study the details of a certain event/historical character. It is the detail that makes history real. The absence of historical imagination in students has an adverse effect on their learning. So the teacher should make history real, supporting the students to develop a wide range of educational skills, comprehension, analysis, synthesis, and extra foliation.

Generally, the perceptions of instructors and students' concerning learning history through discussion methods can be considered positive. For instance, many instructors and students said that they liked group learning and preferred to be taught by this method. However, some students were still not sure about that or preferred the lecturing method. The reasons mentioned above, along with the drawbacks of learning history by using group discussion, maybe some of the reasons why some students disagreed with the social and academic benefits of using cooperative learning.

\section{Results of Document Analysis}

Besides interviews, participant observation, and focus group discussions, the researcher included both primary and secondary written documents in the study. Many written materials related to the importance of group discussion methods of teaching and learning history lessons in the classroom were significantly assessed. Many written sources revealed that teaching history lessons by using discussion methods in the classroom can enhance the academic performance and critical thinking of the teacher-educators in their real life. Results from many published and unpublished sources indicate that learning history lessons through discussion methods of teaching in the classroom can give extra confidence for doing independent works and help to develop the interpersonal skills of the learners and the subject teachers. This does not mean that teaching and learning history lessons through the lecture methods are ignored. Therefore, the data collected through these methods would be carefully examined, cross-checked, interpreted, and analysed.

\section{Classroom Discussion as a Curriculum Outcome}

When considering discussion as a curriculum outcome, students' participation in the actual discussion becomes an end in itself. By teaching students how to discuss, the benefits of using discussion in the classroom can be extended to all areas of students' lives. The research on how teachers "teach discussion" is limited. Most that are available is related to citizenship education because discussion provides one way for citizens to interact (Barber, 1989, p. 355-356). If students or citizens are to engage in discussions that allow for the development of opinions and positions on issues common to a group, then competence in the skills of discussion is required. The very act of discussing requires participants to interact in a particular and structured manner. These structured interactions will likely be different from interactions during debates or arguments (Bruce, 1997, p. 6). The beneficial effects of learning through group discussion are not limited to academic gains. Small groups allow students to interact with their peers and consequently enhance social skills. The structured processes involved in cooperative learning promote pro-social skill development and have been linked to gains in student self-esteem (William, 2012, p. 241).

\section{Benefits from the Discussion Method of Teaching History}


The quality of instruction refers to the quality of learning tasks, their appropriateness, and suitability for the desired outcome. For instance, students promote different experiences, levels of ability, maturity, and social and environmental background from elementary to secondary schools. This cannot be avoided by classroom teachers.

Generally, it can be concluded that students stated what they have benefited from the discussion method of teaching and learning history lesson as follows: it offered them a chance to express their thoughts, it helped them to improve their interpersonal skills as well as expand their knowledge and attitude in preparation for future careers, it can help them to find information from a variety of sources in a variety of ways, they also got information from different sources. It was noted that students could ask questions and get information from their subject teachers as well as from their colleagues during the discussion and out of school times, it helps students to learn to check the accuracy of what they read from the text, students may also learn how to respect and listen to other speakers. Hence, this method provides opportunities to speak, share ideas and improve language communication skills and thus improving their selfconfidence as well as their higher-order thinking abilities (Howard, 2015).

\section{CONCLUSION}

On the theoretical level, this study provides empirical support for models about teachers' thinking about the discussion. This fills a gap in conceptual models of teachers' conceptions of discussion by offering knowledge grounded in data. If discussion is to be used in the classroom, then we must know what teachers think about it, how they plan to use it, and what purposes it serves in the classroom. The method of teaching preferred by students could have a great impact on the outcomes that would be eventually achieved by them at the end of a course. Lecturers, therefore, may bear a huge ethical responsibility towards themselves and their students by choosing the most effective method of teaching. The study indicated that the discussion method of teaching assists in fostering intellectual growth, individual expression, and character development. It offers students opportunities to exchange thoughts and views with each other and heightens language proficiency through constant reinforcement and use.

\section{CONFLICT OF INTERESTS}

The author has not declared any form of interest in this work. All sources available in work are duly acknowledged.

\section{ACKNOWLEDGEMENT}

My deepest and heartfelt gratitude goes to my informants, who have been given their time and valuable information for the completion of this case study. They all gave me their primary testimonies concerning 'Challenges and Benefits of Discussion Method of Teaching History Lesson at Teachers' Training Colleges: Injibara College of Teachers Education in Focus'. Moreover, I thank my friends who have encouraged my strong initiation in conducting the Article to locate the problem areas in the history class. Finally, I am very glad to thank the Department of Social Science for material support to fulfil this Article.

\section{REFERENCES}

Amina, M. E. A. The Effect of Lecture and Discussion Methods of Teaching on Learner's Performance in Social Studies in Continuing Education Institution Borno State, Nigeria.

Aschalew, T. (2013). Teachers Perception and Practice of Active Learning in University. An International Multidisciplinary Journal. 1(6).

Barber, B. R. (1989). Public talk and civic action: Education for participation in a strong democracy. Social Education, 53(6).

Bello, J. Y. (1981). Basic principles of teaching. Spectrum Books.

Birhanu Moges, (2019). Practices and challenges of cooperative learning in selected College of Arsi University: As a Motivational Factor on Enhancing Students' Learning. Universal Journal of Psychology, 7(1), 1-17.

Bruce E. Larson, B. (1997). Teachers' Conceptions of Discussion as Method and Outcome. 
Burden, P. R. (2010). Methods for Effective Teaching, Meeting the Needs of All Students. London: Pearson Education.

Khalid A. K., Suhaimi, M., Alsaqqaf, A., \& Jawad, W. (2018). The Use of the Discussion Method at University: Enhancement of Teaching and Learning. International Journal of Higher Education, 7(6), 118-128.

Najmonnisa. (2013). A "Readiness study about cooperative teaching learning practices at schools level in Karachi: Issues and challenges". Un Published PhD Dissertation.

Sadker, M. P., \& Sadker, D. M. (1991). Teachers, Schools, and Society. New York: McGraw-Hill.

Santiago, F. B., \& García, E. M. (2003). Cooperative learning in the teaching of mathematics in secondary education. Educational Action Research, 11(1), 93-120.

William, D. (2012). The Effects of Cooperative Learning on the Classroom Participation of Students Placed at Risk for Societal Failure. Online Submission, 2(4), 239-246. 